Original Research Article

\title{
Drug utilization pattern and physician adherence to treatment guidelines in inpatients with urinary tract infection
}

\author{
Ajitha Sharma ${ }^{1 *}$, Shweta Oommen ${ }^{2}$
}

${ }^{1}$ Department of Pharmacology, Kanachur Institute of Medical Sciences, Mangalore, India ${ }^{2}$ Department of Pharmacology, Pondicherry Institute of Medical Sciences, Puducherry, India

Received: 17 December 2017

Revised: 13 January 2018

Accepted: 29 January 2018

\section{*Correspondence to:}

Dr. Ajitha Sharma,

Email: drajithasharma@ gmail.com

Copyright: (C) the author(s), publisher and licensee Medip Academy. This is an openaccess article distributed under the terms of the Creative Commons Attribution NonCommercial License, which permits unrestricted noncommercial use, distribution, and reproduction in any medium, provided the original work is properly cited.

\begin{abstract}
Background: Mainstay of management in urinary tract infection (UTI) is antibiotics and it is seen in recent years that antibiotic resistance is increasing. However, very few treatment guidelines exist for UTI and often treating physicians may not adhere to these guidelines. Aims: Current study was undertaken to analyze antimicrobial prescription pattern and utilization, and check for physician adherence to treatment guidelines in UTI.

Methods: This retrospective, record-based study was carried out in a tertiary care hospital in inpatients with UTI. Tabulated data was analyzed using WHO core drug prescribing indicators and Anatomical Therapeutic Chemical/ Defined Daily Dose (ATC/DDD) index. Adherence to treatment guidelines was assessed using Indian Standard Treatment Guidelines for Urology. Data documented in SPSS software was analyzed using $\chi 2$-test and multinomial logistic regression.

Results: Among 364 patients included in study, equal incidence of UTI was seen in both sexes (male to female ratio 1.02:1). Prolonged hospital stay ( $>7$ days) was associated with elderly age group $(\mathrm{OR}=3.09$, CI95\% 1.83-5.21), complicated UTI $(\mathrm{OR}=8.11$, CI95\% 4.62-14.24), ESBL-producing E. coli $(\mathrm{OR}=3.07$, CI95\% 1.585.94), non-adherence to treatment guidelines ( $\mathrm{OR}=8.65$, CI95\% 4.19-17.84), and presence of comorbid conditions like diabetes mellitus (OR=4.89, CI95\% 3.05$7.82)$, benign prostatic hypertrophy $(\mathrm{OR}=2.76$, CI95\% 1.36-5.59) and uterovaginal prolapse $(\mathrm{OR}=8.33$, CI95\% 2.28-30.45). Average number of drugs prescribed per encounter was 1.59 , while drugs prescribed by generic name and from essential drug list were $98.1 \%$ and $70.69 \%$ respectively. Majority of prescriptions $(87.6 \%)$ adhered to standard treatment guidelines. Prescribed daily dose (PDD) and defined daily dose (DDD) were equal for most antibiotics prescribed.

Conclusions: Majority of prescriptions were adhering to treatment guidelines but the need to prescribe using generic name and from essential drug list should be emphasised upon.
\end{abstract}

Keywords: Antibiotic, ATC-DDD system, Drug utilization pattern, Escherichia coli, Treatment guidelines adherence, Urinary tract infection

\section{INTRODUCTION}

Urinary tract infection (UTI) is one of the most common infections affecting humans and is one of the leading causes of both community acquired and nosocomial infections, for patients admitted to hospitals in United States. ${ }^{1}$ It is estimated that about 150 million UTIs are reported every year worldwide. ${ }^{2,3}$ Furthermore, it was found that $40 \%$ of all hospital acquired infections were UTIs and $10-12 \%$ of patients hospitalised in urological wards have a healthcare-associated infection.

Drug utilization is defined by the WHO as the "marketing, distribution, prescription, and use of drugs in society, with 
special emphasis on the resulting medical, social, and economic consequences". Drug utilization studies help to recognize and report irrational prescribing, which adds on to patient morbidity and economic burden. ${ }^{4}$ Among the current available methods, the Anatomical Therapeutic Chemical/ Defined Daily Dose (ATC/DDD) index developed by the World Health Organization is most important and reliable. ${ }^{5}$ Along with this, the assessment of drug use patterns using WHO core drug use indicators is equally important to promote rational drug use. ${ }^{6}$

The defined daily dose (DDD) is the presumed average maintenance dose per day for a drug in its main indication for adults and is usually denoted with a specific population size denominator such as patient days or bed days. The chief disadvantage is that DDD neither reflects the recommended, nor the actual prescribed daily dose (PDD) for individual patients or specific patient populations. ${ }^{7}$ Hence it is ideal to calculate DDD and to determine its variation from the PDD.

Though regularly updated guidelines and recommendations for UTI management exist, poor adherence to these guidelines is seen in common clinical practice. Hence the need for periodic audits to identify critical issues, sub-optimal behaviour and provide solution to problems. ${ }^{8}$ Though a few drug utilization studies are being reported from the Indian subcontinent, there is need for constant monitoring and documenting of prescription practices from various parts of the country. Hence the current study was undertaken with the following objectives:

- To assess drug prescription pattern in inpatients of UTI using the WHO core drug prescribing indicators.

- To assess the antimicrobial utilization in UTI by the ATC/DDD system.

- To check for physician adherence to treatment guidelines using the Indian Standard Treatment Guidelines for Urology.

\section{METHODS}

This retrospective, descriptive, record-based study was conducted in a tertiary care hospital in south India from January to December 2015. The Institutional Ethics Committee clearance was obtained for the study. A waiver of consent was obtained from the same. Subjects aged $\geq 18$ years, admitted with a provisional diagnosis of urinary tract infection and positive urine culture reports were included in the study. Pregnant women with UTI were excluded from the study. The demographic details of patients, presence of comorbid conditions predisposing to development of UTI, treatment details, duration of hospital stay and urine culture report were noted from the case records.

The prescriptions were checked for rationality using the WHO core drug prescribing indicators, which are as follows: ${ }^{9}$
1. Average number of drugs prescribed per encounter was calculated by dividing total number of drug products prescribed by number of encounters surveyed.

2. Percentage of drugs prescribed by generic name was calculated by dividing number of drugs prescribed by generic name by total number of drugs prescribed, multiplied by 100 .

3. Percentage of encounters with an antibiotic prescribed was calculated by dividing number of patient encounters in which an antibiotic was prescribed by total number of encounters surveyed, multiplied by 100 .

4. Percentage of encounters with an injection prescribed was calculated by dividing number of patient encounters in which an injection was prescribed by total number of encounters surveyed, multiplied by 100.

5. Percentage of drugs prescribed from an essential drug list (EDL) was calculated by dividing number of products prescribed from EDL by total number of drugs prescribed, multiplied by 100 .

Physician adherence to the treatment guidelines was assessed using the Indian Standard Treatment Guidelines for Urology. ${ }^{10}$ The ATC classification for the prescribed antibiotics and DDD were noted and, PDD and DDD/1000 inhabitants/day was calculated for the current study.

\section{Statistical analysis}

The data collected was tabulated and analyzed using Statistical Package for the Social Sciences (SPSS), version 20.0 (IBM Corp., Armonk, NY, USA). Statistical analysis was performed using descriptive statistics, and $\chi 2$-test was used for testing group differences, with $\mathrm{p} \leq 0.05$ set as the level of statistical significance. Results were expressed as percentages, frequencies and mean \pm SD. Variables associated with a longer duration of hospital stay that showed statistically significant difference between groups were entered into the final model of the multivariate logistic regression analysis, which was used to compute odds ratio (OR) and $95 \%$ confidence intervals $(95 \% \mathrm{CI})$ to assess the independent associations of these variables with a prolonged hospital stay.

\section{RESULTS}

Among a total of 428 patients diagnosed with UTI in the institute during the study period, 364 patients only were included in the current study, as the remaining subjects did not fulfil the inclusion criteria.

It was found that there was equal distribution gender-wise (male to female ratio was 1.02:1). Highest number of study subjects belonged to the age group of 18-30 years (26.1\%), followed by 51-60 years (19.8\%) (Table 1).

The commonest causative organism was Escherichia coli (78\%), followed by extended spectrum beta-lactamase 
producing Escherichia coli $(7.9 \%)$, Klebsiella pneumoniae (4.8\%), Enterococcus faecalis (4.4\%), Candida albicans (2.6\%), Pseudomonas aeruginosa (1.2\%) and Staphylococcus aureus (1.1\%).

Majority of them had a lower UTI $(97.3 \%)$. More than half of the study subjects $(54.9 \%)$ had a complicated UTI. About one-third of the patients were diabetic (37.6\%), while some others had various comorbid conditions predisposing to the development of UTI It was found that majority of the prescriptions $(87.6 \%)$ adhered to the treatment guidelines (Table 2).
Table 1: Age and gender distribution of study subjects $(n=364)$.

\begin{tabular}{|c|c|c|c|c|}
\hline \multicolumn{2}{|c|}{ Variable } & Number & Percentage & $\begin{array}{l}\text { p } \\
\text { value* }\end{array}$ \\
\hline \multirow{2}{*}{ Gender } & Male & 184 & 50.5 & \multirow{2}{*}{0.78} \\
\hline & Female & 180 & 49.5 & \\
\hline \multirow{6}{*}{$\begin{array}{l}\text { Age } \\
\text { groups } \\
\text { (in } \\
\text { years) }\end{array}$} & $18-30$ & 95 & 26.1 & \multirow{6}{*}{0.01} \\
\hline & $31-40$ & 49 & 13.5 & \\
\hline & $41-50$ & 50 & 13.7 & \\
\hline & $51-60$ & 72 & 19.8 & \\
\hline & $61-70$ & 65 & 17.9 & \\
\hline & $>70$ & 33 & 9.1 & \\
\hline
\end{tabular}

*Statistical significance was considered at $\mathrm{p} \leq 0.05$. Statistically significant $\mathrm{p}$ values indicated by bold.

Table 2: Disease and treatment profile in study subjects $(n=364)$.

\begin{tabular}{|c|c|c|c|}
\hline \multicolumn{2}{|l|}{ Variable } & Number & $\%$ \\
\hline \multirow{2}{*}{ UTI site } & Lower urinary tract & 354 & 97.3 \\
\hline & Upper urinary tract & 10 & 2.7 \\
\hline \multirow{2}{*}{ Type of UTI } & Uncomplicated & 164 & 45.1 \\
\hline & Complicated & 200 & 54.9 \\
\hline \multirow{5}{*}{$\begin{array}{l}\text { Comorbid conditions } \\
\text { predisposing to UTI }\end{array}$} & Diabetes mellitus & 137 & 37.6 \\
\hline & Benign prostatic hypertrophy & $35 / 184$ & 19.0 \\
\hline & Renal calculi & 14 & 3.8 \\
\hline & Utero-vaginal prolapse with/ without cystocoele/ rectocoele & $14 / 180$ & 7.8 \\
\hline & Acute/ chronic renal injury & 21 & 5.8 \\
\hline \multirow{2}{*}{$\begin{array}{l}\text { Urine culture } \\
\text { sensitivity pattern }\end{array}$} & Sensitive & 323 & 88.7 \\
\hline & Resistant & 41 & 11.3 \\
\hline \multirow{3}{*}{$\begin{array}{l}\text { Duration of hospital } \\
\text { stay }\end{array}$} & $1-3$ days & 115 & 31.6 \\
\hline & 4-7 days & 158 & 43.4 \\
\hline & $>7$ days & 91 & 25 \\
\hline \multirow{2}{*}{$\begin{array}{l}\text { Adherence to } \\
\text { treatment guidelines }\end{array}$} & Yes & 319 & 87.6 \\
\hline & No & 45 & 12.4 \\
\hline \multicolumn{2}{|c|}{ Duration of treatment $($ mean $\pm S D)$} & $9.06 \pm 3.7$ & \\
\hline
\end{tabular}

UTI - Urinary tract infection

Table 3: Multivariate logistic regression model with longer duration of hospital stay ( $>7$ days) as the dependent variable $(n=364)$.

\begin{tabular}{|c|c|c|c|c|c|c|c|}
\hline \multicolumn{2}{|c|}{ Independent variables } & B & Wald & $\begin{array}{l}\text { p } \\
\text { value* }\end{array}$ & $\begin{array}{l}\text { Odds } \\
\text { ratio }\end{array}$ & $95 \% \mathrm{CI}$ & $\begin{array}{l}\% \text { variance (Nagelkerke } \\
\text { pseudo } \mathbf{R}^{2} \text { ) }\end{array}$ \\
\hline \multicolumn{2}{|c|}{ Age $>65$ years } & 1.13 & 17.91 & $<0.001$ & 3.09 & $1.83-5.21$ & 0.067 \\
\hline \multicolumn{2}{|c|}{ Gender (males) } & -0.03 & 0.02 & 0.89 & 0.97 & $0.62-1.5$ & $<0.001$ \\
\hline \multirow{5}{*}{$\begin{array}{l}\text { Comorbid } \\
\text { conditions }\end{array}$} & Diabetes mellitus & 1.59 & 43.7 & $<0.001$ & 4.89 & $3.05-7.82$ & 0.17 \\
\hline & $\begin{array}{l}\text { Benign prostatic } \\
\text { hypertrophy }\end{array}$ & 1.02 & 7.95 & 0.005 & 2.76 & $1.36-5.59$ & 0.03 \\
\hline & Renal calculi & -0.59 & 0.78 & 0.38 & 0.56 & $0.15-2.04$ & 0.003 \\
\hline & $\begin{array}{l}\text { Utero-vaginal prolapse } \\
\text { with/without cystocoele }\end{array}$ & 2.12 & 10.26 & 0.001 & 8.33 & $2.28-30.45$ & 0.049 \\
\hline & $\begin{array}{l}\text { Acute/chronic renal } \\
\text { injury }\end{array}$ & 1.53 & 10.2 & 0.001 & 4.6 & $1.8-11.72$ & 0.042 \\
\hline \multicolumn{2}{|c|}{ Complicated UTI } & 2.09 & 53.17 & $<0.001$ & 8.11 & $4.62-14.24$ & 0.237 \\
\hline \multicolumn{2}{|c|}{ Upper UTI } & -0.12 & 0.03 & 0.87 & 0.89 & $0.23-3.51$ & $<0.001$ \\
\hline \multicolumn{2}{|c|}{$\begin{array}{l}\text { ESBL-producing } E \text {. coli in urine } \\
\text { culture }\end{array}$} & 1.12 & 11.02 & 0.001 & 3.07 & $1.58-5.94$ & 0.042 \\
\hline \multicolumn{2}{|c|}{ Non-adherence to treatment guidelines } & 2.16 & 34.1 & $<0.001$ & 8.65 & $4.19-17.84$ & 0.148 \\
\hline
\end{tabular}

*Statistical significance was considered at $p \leq 0.05$. Statistically significant $\mathrm{p}$ values indicated by bold. UTI-Urinary tract infection. 
Table 4: The WHO core prescribing indicators assessed for drug prescriptions $(n=364)$.

\begin{tabular}{|llll|}
\hline Prescribing indicators assessed & $\begin{array}{l}\text { Total drugs/ } \\
\text { encounters }\end{array}$ & $\begin{array}{l}\text { Average/ } \\
\text { percentage }\end{array}$ & $\begin{array}{l}\text { Standard derived } \\
\text { or ideal }\end{array}$ \\
\hline Average number of drugs per encounter & 580 & 1.59 & $1.6-1.8$ \\
\hline Percentage of drugs prescribed by generic name & 569 & 98.1 & 100 \\
\hline Percentage of encounters with antibiotics & 580 & 100 & $20-26.8$ \\
\hline Percentage of encounters with injections & 209 & 36.03 & $13.4-24.1$ \\
\hline Percentage of drugs from essential drug list & 410 & 70.69 & 100 \\
\hline
\end{tabular}

Table 5: Antibiotic consumption in the study population $(n=364)$.

\begin{tabular}{|c|c|c|c|c|c|}
\hline Antibiotic used & $\begin{array}{l}\text { Dose and route of } \\
\text { administration }\end{array}$ & ATC code & $\begin{array}{l}\text { DDD } \\
\text { (mg) }\end{array}$ & $\begin{array}{l}\text { PDD } \\
\text { (mg) }\end{array}$ & $\begin{array}{l}\text { DDD/ } 1000 \\
\text { inhabitants/ day }\end{array}$ \\
\hline \multicolumn{6}{|l|}{ Fluoroquinolones } \\
\hline Norfloxacin & Oral & J01MA06 & 800 & 800 & 2.22 \\
\hline Ciprofloxacin & Oral & J01MA02 & 1000 & 1000 & 3.83 \\
\hline Ofloxacin & Oral & J01MA01 & 400 & 400 & 4.78 \\
\hline Levofloxacin & Oral & J01MA12 & 500 & 1000 & 1.73 \\
\hline \multicolumn{6}{|l|}{ Cephalosporins } \\
\hline Ceftriaxone & Parenteral & J01DD04 & 2000 & 2000 & 1.05 \\
\hline Cefoperazone+Sulbactam & Pareneteral & J01DD62 & 4000 & 4500 & 17.78 \\
\hline Cefepime & Parenteral & J01DE01 & 2000 & 2000 & 0.05 \\
\hline Cefotaxime & Parenteral & J01DD01 & 4000 & 400 & 0.01 \\
\hline Cefixime & Oral & J01DD08 & 400 & 400 & 0.34 \\
\hline \multicolumn{6}{|l|}{ Penicillins } \\
\hline Piperacillin+Tazobactam & Parenteral & J01CR05 & 14000 & 13500 & 0.22 \\
\hline Amoxicillin clavulanate & Parenteral & J01CR02 & 3000 & 2305 & 0.03 \\
\hline Ampicillin & Oral & J01CA01 & 2000 & 1000 & 0.11 \\
\hline Cloxacillin & Oral & J01CF02 & 2000 & 2000 & 0.04 \\
\hline \multicolumn{6}{|l|}{ Carbapenems } \\
\hline Imipenem & Parenteral & J01DH51 & 2000 & 1875 & 0.9 \\
\hline Meropenem & Parenteral & J01DH02 & 2000 & 1500 & 0.04 \\
\hline Co-trimoxazole & Oral & J01EE01 & 4 UD & $4 \mathrm{UD}$ & - \\
\hline \multicolumn{6}{|l|}{ Tetracycline } \\
\hline Doxycycline & Oral & J01AA02 & 100 & 200 & 2.18 \\
\hline \multicolumn{6}{|l|}{ Aminoglycoside } \\
\hline Amikacin & Parenteral & J01GB06 & 1000 & 875 & 2.57 \\
\hline \multicolumn{6}{|l|}{ Nitrofuran derivative } \\
\hline Nitrofurantoin & Oral & J01XE01 & 200 & 200 & 7.26 \\
\hline \multicolumn{6}{|l|}{ Oxazolidinone } \\
\hline Linezolid & Oral & J01XX08 & 1000 & 1200 & 0.45 \\
\hline \multicolumn{6}{|l|}{ Triazole derivative } \\
\hline Fluconazole & Oral & $\mathrm{J} 02 \mathrm{AC} 01$ & 200 & 235 & 1.24 \\
\hline \multicolumn{6}{|l|}{ Macrolide } \\
\hline Azithromycin & Oral & J01FA10 & 300 & 500 & 0.55 \\
\hline
\end{tabular}

The different antibiotics that were used in the treatment of UTI are depicted in Figure 1. The commonest prescribed were fluoroquinolones $(77.4 \%)$, nitrofurantoin $(32.7 \%)$ and cephalosporins $(29.4 \%)$.

The association of variables with a prolonged hospital stay suggested that elderly age group $(\mathrm{OR}=3.09$, CI 95\% 1.83 -
5.21), complicated UTI (OR=8.11, CI 95\% 4.62-14.24), ESBL-producing $E$. coli in urine culture $(\mathrm{OR}=3.07$, CI $95 \%$ 1.58-5.94), non-adherence to treatment guidelines $(\mathrm{OR}=8.65$, CI 95\% 4.19-17.84), and presence of comorbid conditions like diabetes mellitus $(\mathrm{OR}=4.89$, CI 95\% 3.05$7.82)$, benign prostatic hypertrophy $(\mathrm{OR}=2.76$, CI $95 \%$ 1.36-5.59), utero-vaginal prolapse $(\mathrm{OR}=8.33$, CI $95 \%$ 
2.28-30.45) and acute/chronic renal injury (OR=4.6, CI $95 \%$ 1.8-11.72) had a positive association (Table 3 ).

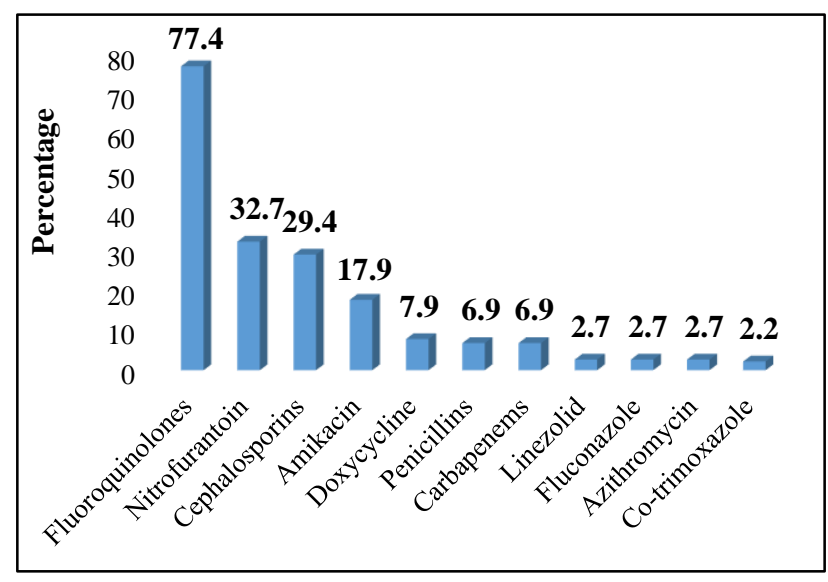

Figure 1: Antibiotics used for treatment of urinary tract infection $(n=364)$.

The rationality of prescriptions was checked using WHO core drug prescribing indicators and the results are depicted in Table 4.

Table 5 illustrates the ATC classification, DDD, PDD and DDD/1000 inhabitants/day of the prescribed antibiotics. It was found that PDD was equal to the DDD for most antibiotics prescribed like fluoroquinolones, cephalosporins, nitrofurantoin and co-trimoxazole. A few antibiotics like doxycycline, linezolid, fluconazole and azithromycin had a PDD higher than the DDD, while yet others like penicillins, carbapenems and amikacin had a PDD lower than the DDD.

\section{DISCUSSION}

In the current study it was seen that UTIs were almost equally distributed in both genders whereas in some other studies a higher incidence was seen in women, while yet other studies reported more incidence in men. ${ }^{11-15}$ The highest incidence was seen in the age group of 18-30 years, which is similar to that was reported, while other studies reported more incidence in a higher age group. ${ }^{3,11,16}$ The commonest causative organism was found to be Escherichia coli which is in concordance with other reports. ${ }^{2,16-18}$ ESBL producing $E$. coli was the next common pathogen, however the incidence was less as compared to other studies. ${ }^{2,19}$ Incidence of various associated risk factors for developing UTI found in the study like diabetes mellitus and renal calculi was comparable with that reported. ${ }^{20}$

Development of standard treatment guidelines for therapy of common infections of public health importance and adhering to these guidelines becomes very important in preventing development of antibiotic resistance. ${ }^{21}$ The Indian Standard Treatment Guidelines for Urology has listed the antibiotics that can be used for treatment of UTI and the recommended treatment duration. Majority of the prescriptions in the current study were found to be adhering to the above-mentioned guidelines. This finding is comparable to that found in a study, and is much higher than those reported elsewhere. ${ }^{22-24}$ Commonest prescribed drugs were cephalosporins, nitrofurantoin and fluoroquinolones, which are all recommended antibiotics for treatment of UTI and findings are in accordance with other similar studies. ${ }^{8,16,25}$

Various factors like elderly age group, complicated UTI, UTI associated with risk factors, non-adherence to treatment guidelines and ESBL-producing E. coli in urine culture, were found to be associated with a prolongation of hospital stay in UTI infected patients. This is akin to the findings reported by other studies done in different settings. $^{26,27}$ As per the WHO core drug prescribing indicators, average number of drugs per encounter and those prescribed by generic name were close to the ideal values mentioned. As the main management of UTI is entirely comprised of antibiotics, it cannot be compared with the ideal values set by WHO. Percentage of encounters with injections was higher, while drugs prescribed from essential drug list were lower than the ideal values of WHO prescribing indicators. These findings are higher than those reported by other studies..$^{25,28}$

The antibiotic consumption was calculated using DDD/1000 inhabitants/day and was compared with PDD. In ideal situations, the PDD should be equal to the standard DDD. In the present study, it was found that most of the prescribed antibiotics had a PDD equal to that of the recommended DDD. A few of the antibiotics like doxycycline and azithromycin had a PDD more than that of the suggested DDD, while others like Penicillins and carbapenems had a PDD lower than the commended DDD. In antibiotic treatment regimens, it is common to see a variation between the DDD and PDD as therapy depends on multiple factors like severity of disease, presence of comorbid conditions that complicate the clinical scenario and national treatment guidelines. These findings of the current study are comparable to results of other previous studies. ${ }^{29,30}$

The study describes the prescribing patterns and physician adherence to treatment guidelines in a single setting and the results cannot be generalised. Moreover, the focus of the study was on inpatients, in whom usually the infection is more severe than those treated on an outpatient basis. A comparison between the two groups would have been ideal. However, the study does enhance the existing literature by providing valuable information on the current trends in management of UTIs.

\section{CONCLUSION}

In conclusion, periodic audits and surveys are very essential to determine prescription errors in order to prevent development of antibiotic resistance to a certain extent. The need to adhere to standard treatment guidelines 
and prescribe from the essential drug list, using generic names has to be impressed upon treating physicians.

Funding: No funding sources

Conflict of interest: None declared

Ethical approval: The study was approved by the Institutional Ethics Committee

\section{REFERENCES}

1. Najar MS, Saldanha CL, Banday KA. Approach to urinary tract infections. Indian $\mathbf{J}$ Nephrol. 2009;19(4):129-39.

2. Sood S, Gupta R. Antibiotic Resistance Pattern of Community Acquired Uropathogens at a Tertiary Care Hospital in Jaipur, Rajasthan. Indian J Community Med. 2012;37(1):39-44.

3. Prakash D, Saxena RS. Distribution and antimicrobial susceptibility pattern of bacterial pathogens causing urinary tract infection in urban community of Meerut city, India. ISRN Microbiol. 2013;2013:749629.

4. Truter I. A Review of Drug Utilization Studies and Methodologies. Jordan Journal of Pharmaceutical Sciences. 2008;1(2):91-104.

5. Sozen H, Gonen I, Sozen A, Kutlucan A, Kalemci S, Sahan M. Application of ATC/DDD methodology to evaluate of antibiotic use in a general hospital in Turkey. Ann Clin Microbiol Antimicrob. 2013;12:23.

6. Desalegn AA. Assessment of drug use pattern using WHO prescribing indicators at Hawassa University teaching and referral hospital, south Ethiopia: a crosssectional study. BMC Health Serv Res. 2013;13:170.

7. Liem TBY, Heerdink ER, Egberts ACG, Rademaker CMA. Quantifying antibiotic use in paediatrics: a proposal for neonatal DDDs. Eur J Clin Microbiol Infect Dis. 2010;29:1301-3.

8. Ussai S, Rizzo M, Liguori G, Umari P, Pavan N, Trombetta C, et al. Antibiotic Treatment of Urinary Tract Infections (UTIs) In Primary Care: An Italian Pilot Study. J Pharmacovigilance. 2016;4(4):215.

9. World Health Organization. How to Investigate Drug Use in Health Facilities: Selected Drug Use Indicators. Available at: http://apps.who.int/medicinedocs/en/d/Js2289e/3.1.ht ml [accessed December 17, 2017].

10. Standard Treatment Guidelines Urology. Govt. of India: Ministry of Health \& Family Welfare 2011. Available at: http://clinicalestablishments.nic.in/WriteReadData/17 .pdf [accessed December 17, 2017].

11. Ahmed SM, Jakribettu RP, Koyakutty S, Arya B, Shakir VPA. Urinary tract infections - An overview on the prevalence and the anti-biogram of gram negative uropathogens in a tertiary care centre in North Kerala, India. J Clin Diagn Res. 2012;6(7):1192-5.

12. George CE, Norman G, Ramana GV, Mukherjee D, Rao T. Treatment of uncomplicated symptomatic urinary tract infections: Resistance patterns and misuse of antibiotics. J Family Med Prim Care. 2015;4(3):416-21.
13. Dutta SB, Beg MA, Bawa S, Kaur A. Drug utilization study in genitourinary infections used as a teaching tool for rational therapy for MBBS students in a Medical College at Dehradun, Uttarakhand. Int J Basic Clin Pharmacol. 2015;4(2):236-9.

14. John LJ, Devi P, John J, Guido S. Drug utilization study of antimicrobial agents in medical intensive care unit of a tertiary care hospital. Asian J Pharm Clin Res. 2011;4(2):81-4.

15. Santra S, Agrawal D, Kumar S, Mishra SS. A Study on the Drug Utilization Pattern in Patients with Chronic Kidney Disease with Emphasis on Antibiotics. J Integr Nephrol Androl. 2015;2(3):85-9.

16. Aypak C, Altunsoy A, en Duzgun N. Empiric antibiotic therapy in acute uncomplicated urinary tract infections and fluoroquinolone resistance: a prospective observational study. Ann Clin Microbiol Antimicrob. 2009;8:27.

17. Laupland KB, Ross T, Pitout JD, Church DL, Gregson DB. Community-onset urinary tract infections: a population-based assessment. Infection. 2007;35(3):150-3.

18. Linhares I, Raposo $\mathrm{T}$, Rodrigues A, Almeida A. Frequency and antimicrobial resistance patterns of bacteria implicated in community urinary tract infections: a ten-year surveillance study (2000-2009). BMC Infect Dis. 2013;13:19.

19. Timothy OO, Olusesan FJ, Adesola BO, Temitayo AA, David FO, Ige OO. Antibiotic resistance pattern of bacterial isolates from cases of urinary tract infections among hospitalized and out-patients at a tertiary health facility in South Western Nigeria. Annals of Tropical Medicine and Public Health 2014;7(2):130-5.

20. Prakasam AKC, Kumar KGD, Vijayan M. A Cross Sectional Study on Distribution of Urinary Tract Infection and Their Antibiotic Utilisation Pattern In Kerala. Int J Pharm Tech Res. 2012;4(3):1309-16.

21. National Treatment Guidelines for Antimicrobial Use in Infectious Diseases. National Centre for Disease Control 2016. Available at: http://www.ncdc.gov.in/writereaddata/linkimages/A MR_guideline7001495889.pdf [accessed December 17, 2017].

22. Jan IS, Cheng SH, Hsu HC, Hsueh PR. Physicians' adherence to guidelines for empirical treatment of urinary tract infection in Taiwan. $\mathrm{J}$ Microbiol Immunol Infect. 2007;40:532-6.

23. Kahan E, Kahan NR, Chinitz DP. Urinary tract infection in women-physician's preferences for treatment and adherence to guidelines: a national drug utilization study in a managed care setting. Eur J Clin Pharmacol. 2003;59(8-9):663-8.

24. Kahan NR, Chinitz DP, Kahan E. Physician adherence to recommendations for duration of empiric antibiotic treatment for uncomplicated urinary tract infection in women: a national drug utilization analysis. Pharmacoepidemiol Drug Saf. 2004;13(4):239-42.

25. Bhamare AB, Bhamankar KH, Khairnar AS. Drug Utilization $90 \%$ of Urinary Tract Infections Drugs - A 
Simple Method for Assessing the Quality of Drug Prescribing. Research J Pharm Tech. 2011;4(8):132830.

26. Lautenbach E, Patel JB, Bilker WB, Edelstein PH, Fishman NO. Extended-spectrum beta-lactamaseproducing Escherichia coli and Klebsiella pneumoniae: risk factors for infection and impact of resistance on outcomes. Clin Infect Dis. 2001;32(8):1162-71.

27. Yang YS, Ku CH, Lin JC, Shang ST, Chiu CH, Yeh $\mathrm{KM}$, et al. Impact of Extended-spectrum $\beta$-lactamaseproducing Escherichia coli and Klebsiella pneumoniae on the outcome of community-onset bacteremic urinary tract infections. J Microbiol Immunol Infect. 2010;43(3):194-9.

28. Tessema Z, Teshale C, Hawaze S. A retrospective review of antibiotic utilization in adult medical wards of a primary care hospital in Ethiopia. Int $\mathrm{J}$ Pharm. 2014;4(1):56-62.

29. Naik H, Devi A, Sudha MJ. Pattern of Antibiotic prescription in Urinary Tract Infection. Indian Journal of Pharmacy and Pharmacology. 2016;3(2):59-62.

30. Gidamudi SS, Jadhav SA, Khanwelkar CC, Thorat VM, Desai RR, Naik HG. Drug utilization study on antimicrobial use in urinary tract infection. National Journal of Medical Research. 2015;5(3):216-21.

Cite this article as: Sharma A, Oommen S. Drug utilization pattern and physician adherence to treatment guidelines in inpatients with urinary tract infection. Int J Basic Clin Pharmacol 2018;7:363-9. 